\title{
A propósito de Dioniso y Apolo. Mismidad y Otredad: el juego de las tensiones ${ }^{1}$
}

\author{
María Cecilia Colombani \\ Universidad Nacional de Mar del Plata \\ Universidad de Morón \\ mcolombani@unimoron.edu.ar
}

\section{RESUMO}

O propósito do trabalho seguinte consiste em pensar a tensão entre Apolo e Dioniso à luz de certas configurações identitárias das duas divinidades, rastreando traços vinculados à noção de alteridade e "mesmidade", a partir de um horizonte antropológico.

PALAVRAS-CHAVE: Apolo; Dioniso; "mesmidade"; alteridade; identidade.

\section{Introducción}

El propósito del siguiente trabajo consiste en pensar la tensión entre Apolo y Dioniso a la luz de ciertas configuraciones identitarias de ambas divinidades, rastreando rasgos vinculados a la noción de otredad y mismidad, desde un horizonte antropológico.

A partir del enunciado, recorreremos, en primer lugar, un cierto marco teórico en torno a la díada aludida, para luego, en segundo momento recorrer los aspectos "otros" de ambas divinidades y los rasgos que se enmarcan en el horizonte de "lo mismo", para mostrar la matriz compleja y paradojal de ambas figuras.

En el campo de la Otredad, enfatizaremos en Apolo la terribilidad que lo caracteriza en la dimensión mántica, que él preside como ningún otro dios, siguiendo el análisis que propone Giorgio Colli, en su intento de disputa filológica con el Nietzsche de El origen de la tragedia. ${ }^{2}$

En el caso de Dioniso, seguiremos la huella de la manía para ver su lado más oscuro, su configuración más temible y fantasmagórica.

No obstante, fiel a lo enunciado, bucearemos, en un segundo momento, el campo de la Mismidad, que ambos dioses también parecen encarnar.

\footnotetext{
${ }^{1}$ Conferencia pronunciada en el Programa de Pós-Graduación en Letras: Estudios Literarios de la UFMG, el día 23 de septiembre de 2008, agradeciendo la gentil invitación de la Dra. Tereza Virgínia Barbosa.

${ }^{2}$ Nos referimos al texto de Giorgio Colli El nacimiento de la filosofía (Barcelona: Tusquets, 1987), donde el autor italiano polemiza con Nietzsche en torno a la visión unilateral que el filósofo alemán le otorga a Apolo. Colli problematiza los rasgos apolíneos, señalando la duplicidad de su entramado identitario y mostrando la parcialidad de la lectura nietzscheana, sobre todo al ubicar sólo a Dioniso en el campo de la manía y la crueldad.
} 
En Apolo, rastreamos su condición de constructor-fundador, siguiendo la huella de Marcel Detienne en su reciente texto Apolo con el cuchillo en la mano, ${ }^{3}$ donde aparece un marcado rasgo civilizatorio.

En Dioniso, rastrearemos su dimensión de dispensador del vino, práctica de sesgo civilizatorio, en la medida en que inaugura la práctica simposial.

Los rasgos que emparientan a ambas divinidades con la Mismidad constituyen un pasaporte a la tradición cultural de la ciudad, ya que, tanto el Apolo fundador, como el Dioniso dispensador de la bebida en su punto justo, son arquetipos claves de la consolidación de las póleis.

\section{La cuestión del Otro. El juego de las metáforas}

Tal como anticipamos, proponemos transitar un marco teórico de registro antropológico, para luego, insertar en las consideraciones vertidas, el trabajo crítico sobre ambas divinidades.

Sin duda la Antropología, tanto desde el pasado como en la actualidad, enfrenta la compleja tensión entre la Mismidad y la Otredad como uno de los núcleos dominantes de problematización al interior de su campo disciplinar.

Esta tensión propia del escenario antropológico-filosófico supone y despliega en todas sus peculiaridades la tensión entre la homogeneidad y la heterogeneidad, la semejanza y la desemejanza, la continuidad y la discontinuidad, como díadas no sólo antropológicas, sino también éticas y políticas.

La Mismidad, como eje de poder, consolida la construcción y conservación de la tradición y la transmisión de la memoria tanto individual como colectiva, y constituye el paradigma de las formas en que se expresa o se nos atribuyen las notas de una determinada identidad.

La Otredad, en cambio, dibuja un escenario complejo; su territorio incluye los modos de entrar en relación, visualizar, calificar o descalificar a los otros hombres que

\footnotetext{
${ }^{3}$ En la misma línea de problematización que propone Giorgio Colli, Marcel Detienne (Apolo con el cuchillo en la mano. Una aproximación experimental al politeísmo griego. Madrid: Akal, 2001) analiza la tensión identitaria de Apolo, a punto tal de recuperar un Apolo matarife, tal como el título de la obra permite entrever. Creemos advertir tanto en Colli como en el último Detienne una misma línea de revisión de lecturas unilateralizadas que acotan la multiplicidad de matices que integran el campo identitario de las divinidades.
} 
difieren en sus aspectos físicos exteriores, en sus costumbres y en algunas formas de construir sus identidades. ${ }^{4}$

En ese otro se juegan ciertas dimensiones que pasaremos a enmarcar en un juego de metáforas. Hay en el Otro una cierta dimensión de opacidad, que suele ubicarlo en un punto de irracionalidad. Frente a la racionalidad hegemónica de lo Mismo, el Otro suele aparecer transido por cierta forma de la sin razón o de una racionalidad menor. Si pensamos en el maridaje entre razón y luminosidad, hay algo opaco en ese Otro que se vuelve de algún modo intraducible. He aquí una primera metáfora que llamaremos "metáfora lumínica". Mientras unos alcanzan la luz, otros parecen quedar territorilizados a cierta forma de opacidad y silenciamiento.

La problemática transita, incluso, por una cuestión topológica, ya que la tensión aludida parece resolverse en una "metáfora espacial", que se juega en prácticas de territorialización y desterritorialización. Los sujetos quedan siempre especializados al interior de ciertos tópoi, territorios, según su cualificación antropológica. Los espacios suelen ser funcionales a las utopías clasificatorias y a las necesidades ficcionadas por los dispositivos de poder.

La metáfora implica la perspectiva de un centro como núcleo de instalación de lo Mismo y como preservación del tópos de la identidad, y la perspectiva de un margen como espacio de lo Otro, y como forma de la exclusión-fijación de la diferencia.

Lo diferente suelo ser aquello que atenta contra lo mismo-idéntico, y es por ello que su presencia genera un intenso juego de problematización, que sostiene a la base un sentimiento de temor, phóbos. La xenofobia no hace sino encubrir un fuerte sentimiento de temor frente a lo distinto, xénos. Ya no se trata de una cuestión topológica, sino ontológica. Hay algo en el ser mismo de ese Otro que discontinúa la tranquila familiaridad ontológica que lo Mismo devuelve en su similitud, homogeneidad y semejanza.

La Mismidad construye la familiar consideración autorreferencial de la humanidad y la Otredad interpone la duda de la no humanidad, o de una humanidad disminuida en su plenitud de ser; se trata siempre de cierta e incomodante forma de la anormalidad, de la extrañeza, que rompe las certezas que lo Mismo otorga como suelo firme, como Grund, cimiento, inconmovible para toda construcción identitaria.

\footnotetext{
${ }^{4}$ Para este tema, cf. Belleli, C.; Garreta, M. La trama cultural. Textos de Antropología. Buenos Aires: Caligraf, 1999, p. 15. La tensión Mismidad-Otredad parece ocupar el interés antropológico a partir de la consolidación de la díada aludida como bisagra constituyente de la construcción de lo social.
} 
Lo Otro abre el campo de lo fantasmagórico porque suele estar asociado a la idea de lo extraño. La huella etimológica del término griego xénos nos permite recorrer algunos aspectos de tal paisaje: extraño, extranjero, raro, poco familiar. Al mismo tiempo, ese extraño-extranjero inaugura el relativismo antropológico. Hay algo más que la Mismidad autorreferencial y tautológicamente dominante.

Es al interior del tejido cultural que el Otro se construye, incluso como modo de robustecer la afirmación identitaria de lo Mismo. Pensar al Otro es una forma de mirar aquello opaco, extraño por extranjero y extranjero por extraño, que convoca a una mirada interpretativa, a un gesto de traducción desde la Mismidad, como modo incluso de conjurar su peligrosidad, su paradojal fascinación y su inusual presencia, que viene a discontinuar el apacible tópos de lo Mismo. Pero es al mismo tiempo la mirada necesaria para reafirmarse en un tópos de dominación.

Lo Otro suele tomar la forma de una amenaza en ciernes, con su irrupción portadora de una diferencia que suele no encajar en los habituales órdenes, en las geografías sosegantes, donde se vigila el tópos de la semejanza. La presencia del Otro suele desplegar el páthos, sentimiento, del no reconocimiento, de la intolerancia, de la violencia, como forma de neutralizar la presencia y la palabra de quien no merece ser considerado un par antropológico.

Jean Pierre Vernant incursiona en su magnífico texto La muerte en los ojos en este tema, con decidido perfil antropológico y distingue tres formas de la otredad, situadas en tres figuras míticas de peculiar identidad: Dioniso, Artemisa y Gorgo. Dice el prólogo a propósito del proyecto:

La hipótesis es que cada uno guarda relación, según sus propias modalidades, con lo que el autor llamará, a falta de un término mejor, la alteridad; refleja la experiencia de os griegos con el Otro, bajo las formas que ellos le atribuyeron. ${ }^{5}$

No creemos adulterar el universo de trabajo si pensamos ciertas relaciones a propósito de Dioniso y Apolo desde el marco teórico propuesto, sobre todo allí donde el Otro cobra la dimensión de una radical extrañeza y foraneidad. Dioniso parece ser el más fiel exponente de la alteridad-extranjeridad, ya que:

\footnotetext{
${ }^{5}$ Cf. Vernant, J. P. La muerte en los ojos. Buenos Aires: F.C.E., 2000, p.16.
} 
es la brusca irrupción, en medio de la vida terrena, de aquello que sustrae al hombre de la existencia cotidiana, del curso normal de las cosas, de sí mismo: el disfraz, la mascarada, la borrachera, el juego, el teatro, la zozobra, en fin, el delirio del éxtasis. Dioniso enseña u obliga a devenir otro, a hacer en esta vida, aquí abajo, la experiencia de una evasión hacia una desconcertante foraneidad. ${ }^{6}$

No obstante, más allá de la contundencia de sus rasgos, Apolo lo acompaña en cierto margen de otredad, leído, sobre todo, a partir de la experiencia mántica, donde la manía deja de ser privativa del dionisismo para abrazar el territorio apolíneo, en el marco de una terribilidad, que también arrebata el patrimonio dionisíaco. Si Dioniso puede mostrarse terrible, Apolo también lo hace, extendiendo el tópos de la crueldad.

Dejemos, pues, que ambas configuraciones nos muestren sus lados más oscuros.

\section{Las marcas de la Otredad}

\section{Las huellas del horror}

\section{Dioniso: los signos de la crueldad}

De Tebas al Ática, el territorio es el vasto escenario que Dioniso elige para desplegar su epifanía más cruel. Las marcas del extranjero se hacen notar cuando el desconocimiento que sufre retorna en la manía más álgida. Como un Otro desconocido e ignorado, como un extranjero que nadie registra en su paso foráneo, su acción se vuelve hostil y nadie mejor que Penteo para dar testimonio de ello. Hombres, mujeres y ciudades quedan capturados bajo el mismo efecto menádico, donde la díada desconocimiento-manía domina la escena y sólo la prudencia, sophrosýne, de un anciano augur como Tiresias se desmarca del castigo con el que Dioniso castiga tamaña hýbris, desmesura.

Dios epidémico que puede presentarse como una enfermedad contagiosa que ataca a gran número de personas; enorme poder de contagio, que pone en expansión la enfermedad; rasgos familiares que han acompañado y siguen acompañando las representaciones de la Otredad. El Otro suele ser visto como portador de una enfermedad altamente contagiosa, extraña y poco definida pero enfermedad al fin.

Dios Otro cuyas apariciones escapan a la Mismidad que el culto programado aporta. Tal como expresa Detienne, "hay en Dioniso una pulsión 'epidémica' que lo

\footnotetext{
${ }^{6}$ Cf. Vernant, op. cit., 2000, p. 17.
} 
coloca aparte de los otros dioses de epifanías regulares, programadas y siempre dispuestas en el orden cultural de las fiestas oficiales, y cada una en su tiempo; llegadas sin sorpresas: para los fieles tanto como para los dioses". ${ }^{7}$ He aquí otro rasgo de extranjeridad: su pulsión epidémica, circulando siempre como otro, por fuera del circuito de lo Mismo, apostando a lo irregular, a lo no programado, a lo que escapa a los controles de lo oficial y regular, incluso desafiando el riesgo de ver negada su presencia-pertenencia a la raza de los Inmortales. Este punto se emparienta con el anterior, ya que, es esta alteridad lo que lo obliga permanentemente a dar cuenta de su divinidad ante los hombres.

$\mathrm{Si}$ hemos propuesto el tema de la terribilidad, como marca profunda de la identidad apolínea, Dioniso también cae en episodios ruidosos y frenéticos, sesgados por la crueldad; su irrupción nunca es apacible, por cuanto, "sus primeras epifanías están marcadas por enfrentamientos, por conflictos o por formas de hostilidad que van desde el desprecio, desde el desconocimiento hasta el rechazo declarado y hasta la persecución"8 Magnífica descripción de una situación de Otredad, que guardar rasgos comunes con configuraciones de absoluta vigencia en la construcción simbólica de la otredad.

Más allá del debate en torno a su posible origen tracio, la extranjeridad de Dioniso es una foraneidad intrínseca, "es un extranjero del interior", no un bárbaro. En efecto, "en ninguna parte Dioniso es calificado de dios bárbaro. Aun cuando sus violencias parecen exiliarlo definitivamente a la barbarie" $\mathrm{He}$ aquí otro rasgo característico del imaginario antropológico de la otredad: la configuración de otro intracultural que no parecer encajar en los límites aceptables que la Mismidad construye para garantizar sus certezas.

Sólo unas pocas marcas alcanzan para devolver los aspectos identitarios de un dios que, no obstante, nos tiene reservado otro aspecto, menos violento, más cercano a las necesidades culturales de la polis incipiente.

Pero ahora es el momento de Apolo y de su parentesco "otro" con Dioniso.

\section{Apolo: los signos de la terribilidad}

\footnotetext{
${ }^{7}$ Cf. Detienne, M., Dioniso a cielo abierto, Barcelona: Gedisa, 1986a, p. 22.

${ }^{8}$ Cf. Detienne, op. cit., 1986a, p. 23.

${ }^{9}$ Cf. Detienne, op. cit., 1986a, p. 29.
} 
El Apolo homérico hace su temprana aparición en el poema para marcar y advertir los riesgos de la hýbris, que una vez más aparece en términos de desconocimiento a la divinidad, en este caso, en forma indirecta.

Agamenón, soberano de hombres, ofendió a Crises, sacerdote de Apolo, ofendiendo indirectamente al Señor de Delfos. Leemos en el canto I:

¿Quién de los dioses lanzó a ambos a entablar disputa? El hijo de Lento y de Zeus. Pues, irritado contra el rey, una maligna peste suscitó en el ejército, y perecían las huestes porque al sacerdote Crises había deshonrado el Atrida ${ }^{10}$.

La presencia de Apolo en defensa de su sacerdote, injuriado por el soberano a partir del rapto de su hija, se manifiesta con una crueldad devenida en enfermedad, especie de muerte diferida, indirecta, según la interpretación de Giorgio Colli, intentando desplazar este tipo de crueldad indirecta al corazón mismo de la práctica adivinatoria.

Apolo “descendió de las cumbres del Olimpo, airado en su corazón, con el arco en los hombros y la aljaba, tapada a ambos lados. Resonaron las flechas sobre los hombros del dios irritado, al ponerse en movimiento, e iba semejante a la noche". ${ }^{11}$ Un Apolo negro de ira muestra su cara más terrible, arrojando las flechas sobre el campo de los aqueos y causando una muerte diferida, lenta, nunca inmediata. El nudo de la interpretación de Colli consiste en homologar la acción hostil del episodio homérico con el modo de comportamiento del dios oracular en la economía general del proceder adivinatorio.

La terribilidad del oráculo, su oscuridad, el mensaje críptico, difícil de desentrañar, hablan, no sólo de la hostilidad de un dios que se niega a una comunicación abierta, clara y directa, sino también a una marca identitaria que coloca al dios en ese lugar muy alto que le reconoce Heráclito al hablar del Señor que reina en Delfos. Su mensaje da cuenta de la fractura metafísica que separa a los hombres de los dioses, de la brecha ontológica que el tejido, orden y estructura de las palabras se encargan de recoger. El mensaje oracular, tal como sale de la boca inconexa de la sacerdotisa, "sin risa, ni ornamento, ni unguento", ${ }^{12}$ hiere desde su distancia metafísica e invita al hombre a un desciframiento humano de palabras no humanas. La arquitectura del lógos

${ }^{10}$ Cf. Homero. Ilíada. Traducción de Emilio Crespo Güemes. Madrid: Gredos, 2000 (I v. 8-12).

${ }^{11}$ Cf. Homero, op. cit., v. 44-47.

${ }^{12}$ Cf. Colli, op. cit., p. 33. 
denuncia su procedencia del más allá y se inscribe en una circunstancia excepcional, la manía profética, que ubica a Apolo en el segmento de la locura, viejo patrimonio dionisíaco. Apolo también muestra su rostro maníaco y llama a la sophrosýne, mientras él se permite un acto de hýbris.

Rostro que parece vincular a ambas divinidades en ciertos rasgos que denotan formas de la otredad-terribilidad-hostilidad, sobre un fondo ambiguo y paradojal que parece sostener toda la arquitectura mítica, en esa lógica de la ambigüedad ${ }^{13}$, donde los contrarios, lejos de excluirse, se reconcilian en figuras multisémicas.

Es momento entonces de recuperar los aspectos que ubican a ambos dioses en el marco de la Mismidad; rasgos identitarios, en los cuales el hombre griego se identifica con sus dioses, quienes le aseguran el orden del cósmos.

Apolo devolverá su rostro más luminoso a partir de su gesta fundacional; Dioniso lo hará a partir de sus enseñanzas sobre las cualidades del vino, el bello elemento líquido, que lo emparienta con Démeter, dispensadora del alimento sólido.

En ambos casos, rasgos civilizatorios, sobre una espesura siempre tensionada y paradojal.

\section{Las marcas de la Mismidad}

\section{Las huellas de la civilización}

\section{Dioniso y el elemento líquido}

Inventar el vino parece ser patrimonio dionisíaco, al tiempo que marca el alejamiento de la tierra tebana y de sus rasgos más ásperos para iniciar la visita al Ática como nuevo destino de sus epifanías. "El Dioniso caminante en Ática se presenta bajo una máscara completamente distinta: es un dios discreto, paciente, una potencia benévola y generosa; en las antípodas de su personaje tebano". ${ }^{14}$ Los rasgos que vinculan a Dioniso con el tópos de la alteridad parecen lentamente desdibujarse para recomponerse en la sosegante pertenencia al orden de la Mismidad.

Es el Dioniso más prudente, visitante del rey Icarios, cercano, como anticipáramos, a Deméter, visitante de Celeos, rey de Eleusis, y ambos portadores de los

\footnotetext{
${ }^{13}$ Marcel Detienne en su obra Los maestros de verdad en la Grecia Arcaica (Madrid: Taurus 1986b) hilvana el pasaje del mýthos al lógos a partir del desplazamiento de una "lógica de la ambigüedad" a una "lógica de la no contradicción", hija del advenimiento de la pólis, como medio de producción del nuevo logos emergente.

${ }^{14}$ Cf. Detienne, op. cit., 1986a, p. 61.
} 
alimentos de los hombres: los granos, alimentos cerealeros, y la vid, elementos que pautan la vida civilizada de los mortales.

De todos modos, la llegada de Dioniso al démos de Icarion está, una vez más, marcada por la extrañeza-otredad que venimos persiguiendo. Su presencia es furtiva, extraña, nocturna, imperceptible, marcada por la terribilidad, como huella suficiente para detectar su presencia y que todos registren su aparición, que coincide con el arribo de la primera planta de vid. Es la primera marca del conocimiento del vino que, para alcanzar su civilidad, esto es, su estatuto benévolo, deberá pasar por la mediación del dolor. Sólo el dolor permite el tránsito de lo salvaje a lo civilizado. "En los tiempos de Icarios, el vino aparece ante todo como un veneno violento; y Dioniso que se ha retirado en la sombra deja a los hombres el cuidado de descubrir el poder del vino y del dios que lo habita, sin mostrarse él mismo jamás de frente". ${ }^{15}$ El vino es entregado por vez primera en el marco de una acción violenta, ya que supone la muerte de los convidados por el rey, que termina muerto, a su vez, en manos de sus propios invitados.

En un segundo momento del periplo Ático, Dioniso, es bienvenido a la mesa del rey Anfictión, en compañía de los dioses de la ciudad. Momento privilegiado de Mismidad que aleja la anterior configuración de alteridad extrema.

El Dioniso glorioso rematando su obra, la que comenzó en Icarión el día en que dejó tras de sí la primera vid. El Dioniso sentado a la mesa con Anfictión confía al rey hospitalario lo que no había indicado al anfitrión reinante en los vergeles: el arte de beber el vino, de gustar la bebida nueva revelada a la humanidad. ${ }^{16}$

De lo salvaje a lo civilizado, un mismo dios preside el tránsito; su doble rostro lo ubica en los límites entre lo Mismo y lo Otro. La pura crueldad cede paso a un ritual moderado, que exige la esmerada enseñanza del buen uso del líquido embriagante, práctica transida por la sophrosýne, otrora impensable en el extraño-extranjero.

\section{Apolo y la gesta fundacional}

Es el turno de Apolo y a él parece corresponderle el gesto civilizatorio por excelencia: fundar ciudades, como modo de organizar el tópos humano. El periplo de su madre, Leto, hasta alcanzar Delos, única que acoge a la diosa en su intento de parir un gran hijo, parece repetirse en el destino apolíneo y en su intento de fundar un gran

\footnotetext{
${ }^{15}$ Cf. Detienne, op. cit., 1986a, p. 65.
}

${ }^{16}$ Cf. Detienne, op. cit., 1986a, p. 70. 
templo. Delfos terminará siendo la elegida y nunca más el Señor que reina en ella cederá el lugar mántico por excelencia. Hallar el lugar adecuado para la construcción arroja la imagen de un Apolo fundador, constructor y arquitecto, capaz de ritualizar la gesta, eligiendo el terreno, preparando el territorio, acopiando los materiales para tamaña empresa.

El Apolo trabajador parecer ser una continuidad del trabajo encarnado por su madre. Fatigosa tarea la de una madre. Iris, Ilitía y Leto dando forma a la tarea femenina por excelencia. La mensajera, la nodriza y la madre cumpliendo el ritual que parece delinear el universo de las mujeres; trabajo no exento de fatigas y dolores, rasgos habituales de la dimensión del mismo entre los mortales. Los trabajos se suceden y las tareas no cesan a la hora de fundar el arquetipo de todo nacimiento: las diosas lavaron al recién nacido en agua clara, lo fajaron con lino blanco y lo envolvieron con una cinta de oro, conforme a tan ilustre nacimiento. Temis se suma a las tareas maternales y lo amamanta con néctar y ambrosía con sus manos inmortales. El espectro del trabajo femenino se dibuja en el horizonte olímpico y Leto se regocija de "haber parido un hijo poderoso y capaz de llevar el arco". ${ }^{17} \mathrm{El}$ arco y la cítara son los dos elementos que el mismo Apolo reclama ni bien inicia su tarea itinerante, abandonando el seno materno.

Es el momento de trabajar. Es el instante de crecer y volar de los primeros cuidados femeninos para iniciar la tarea viril por excelencia: recorrer el terreno para construir, sentar los cimientos, levantar paredes, construir el techo, propiciar el albergue, producir marca en el espacio. Apolo con su trabajo cosmifica el tópos, lo ordena, lo delimita para cumplir con su tarea. Se está escribiendo míticamente el relato de la función masculina: propiciar albergue.

"Dicho esto se puso en marcha sobre la tierra de anchos caminos Febo, el de intensa cabellera, el Certero flechador". ${ }^{18}$

El trabajo se inicia, como siempre, con una puesta en movimiento. Alcanzar el fruto tardío del trabajo acabado supone el punto inicial de abandonar el reposo para encaminarse en busca del objeto ansiado. El trabajo apolíneo conlleva una apuesta nomádica que conjura toda forma de sedentarismo. Apolo inicia su periplo, como lo hiciera su madre, y el himno vuelve a convertirse en un regalo cartográfico: ciudades, islas, atalayas, promontorios de alturas eminentes, ríos, que desembocan en el mar, se

${ }^{17}$ Cf. Himnos Homéricos y la Batracomaquia. Traducción de Alberto Bernabé Pajares. Madrid: Biblioteca Básica Gredos, 2001 (Himno Homérico III a Apolo, v. 125-126).

${ }^{18}$ Cf. Himno Homérico III a Apolo, v. 133-135. 
suceden en una detallada grilla de geografías divinas. El Himno delio devuelve la figura triunfal de Apolo reinando soberanamente sobre una Delos que no deja de venerarlo en su magnificencia. Pero el ilustre hijo de Leto y de Zeus va por más: es el destino de los grandes y es el momento del himno pítico, cuando el "señor muy alto que reina en Delfos”, según Heráclito, se dirige precisamente allí para fundar un gran templo.

Así, "se encamina, tañendo la ahuecada forminge, el hijo de la gloriosísima Leto hacia Pito, la rocosa, con sus divinas vestiduras, fragantes de incienso". ${ }^{19}$ Con paso gallardo y arrogante, Apolo continúa su marcha y el Himno se convierte en un extenso catálogo de hazañas de carácter amoroso, al tiempo que describe el nomadismo apolíneo, que termina en Telfusa, un plácido lugar de frondosa arboleda, que agradó al dios. En estos términos sentó las bases de su deseo-decisión:

Telfusa, aquí mismo pienso procurarme un templo hermosísimo, como oráculo para hombres que por siempre traerán hecatombes perfectas, ya sea cuantos habitan el fértil Peloponeso, ya cuantos habitan Europa y en las islas ceñidas por las corrientes, dispuestos a consultar el oráculo. ${ }^{20}$

Parece que ha llegado el momento de poner manos a la obra. El Apolo constructor devolverá toda su tékhne en la construcción de un templo hermosísimo. Pero sólo parece, porque Telfusa, que cree ver amenazada su gloria ante la presencia del Certero, persuade a Apolo para que continúe su búsqueda.

El caminante sigue su marcha y tras largo camino, Apolo se detiene. Ahora sí, tras ardua búsqueda, el espacio aparece y llega finalmente a "Crisa, al pie del nevado Parnaso, una ladera orientada al Céfiro. Por cima de ella se cierne una peña y corre a sus pies un profundo valle, escabroso". ${ }^{21}$

Por fin alcanzó el tópos propicio y así lo hizo saber, ya que ese será el enclave de un templo hermosísimo, "a fin de que sea el oráculo para los hombres", 22 quienes hacia él se dirigirán desde todo el Peloponeso, para recibir la infalible determinación del dios oracular. Ya había declarado lo mismo frente a Telfusa, pero ahora sí la empresa se inicia de la mano de un verbo que parece ser capital a la gesta fundadora.

Un verbo de acción une el conjunto de gestos ejecutados por Apolo desde sus primeros pasos: ktízein. Verbo fundamental de la

\footnotetext{
${ }^{19}$ Cf. Himno Homérico III a Apolo, v. 182-184.

${ }^{20}$ Cf. Himno Homérico III a Apolo, v. 248-252.

${ }^{21}$ Cf. Himno Homérico III a Apolo, v. 283-285.

${ }^{22}$ Cf. Himno Homérico III a Apolo, v. 288.
} 
"fundación”, espacialmente para las ciudades nuevas, a lo largo de la colonización de las tierras de Occidente y las orillas del mar Negro desde el siglo VIII a.C. El campo de ktízein es doble. Por una parte, significa roturar, cultivar, acondicionar. Por otra, construir, edificar, fundar. ${ }^{23}$

La acción no se hace esperar. "Dicho esto, echó los cimientos Febo Apolo, anchos, muy largos, sin fisuras". ${ }^{24}$ Apolo no está solo. El trabajo suele requerir más de una presencia. Como su madre que necesitó de colaboradoras para su trabajo de parto. Trofonio y Agamedes, hijos de Ergino, rey de Orcómeno, se sumaron a la empresa. Trofonios es una vieja divinidad ctónica, con poderes oraculares, que, asimilado por Apolo, pasa a ser constructor de su templo; colocaron un umbral de piedra sobre los cimientos y alrededor elevaron, con sillares de piedra, "para que fuera digno de ser cantado por siempre". ${ }^{25}$

Apolo no detiene su labor. Como corresponde a la tarea de fundación, limpia el terreno de posibles amenazas. Así se dirige a una fuente próxima, la fuente Castalia, y mata con su arco a la Dragona, monstruo salvaje, que causa daño a los hombres. Aparece entonces el Apolo fundador, no sólo porque sienta los cimientos, sino porque civiliza el espacio, lo vuelve habitable, le imprime una marca que lo desplaza del lugar salvaje, habitado por monstruos. El espacio pasa de un registro de marcada Otredad a un estatuto de legitimada Mismidad. El trabajo apolíneo no parece ser exclusivamente manual, de cimentación, sino también estratégico, como lo es el trabajo de un verdadero strategós. También es una tarea civilizatoria limpiar el espacio de las funestas amenazas, de las impurezas; no solo se prepara un terreno topológicamente, sino que se lo desmaleza de sus posibles contaminaciones. Por eso, "le lanzó un poderoso dardo el Soberano Certero, Apolo. Ella, abrumada por terribles dolores, yacía jadeando intensamente y rodando por el suelo". ${ }^{26}$

Apolo nomádico y fundador. Apolo tekhnítes, que conoce como nadie el arte de construir, símbolo mismo del poder. Apolo civilizador desde múltiples vertientes, ya sea por su capacidad de trabajo, convertida en fuerza transformadora de un espacio salvaje que pasa a ser un espacio fundado, esto es ordenado, ya sea por su acción bienhechora de limpiar un espacio de aquellos peligros que vuelven hostil el suelo para los hombres.

\footnotetext{
${ }^{23}$ Cf. Detienne, op. cit., 2001, p.27.

${ }^{24}$ Cf. Himno Homérico III a Apolo, v. 295-296.

${ }^{25}$ Cf. Himno Homérico III a Apolo, v. 298-299.

${ }^{26}$ Cf. Himno Homérico III a Apolo, v. 357-360.
} 
En efecto, "no hay ciudad $<$ fundada $>$, < bien fundada $>$ que no sea al mimo tiempo una tierra roturada, un territorio preparado para el cultivo, un espacio domesticado, civilizado desde el estado salvaje inicial". ${ }^{27}$ Para esto hace falta una tarea que combine fundación, construcción y limpieza. El Apolo constructor se vuelve también civilizador, ampliando el repertorio de trabajos que lo ubican en un hacedor de cultura.

Tanto Apolo, como su madre, cumplen una función socializante. Ambos escogen el espacio, lo preparan, lo convierten en el tópos adecuado para dos acciones ejemplares: el nacimiento, marca cultural por excelencia, y el culto, rasgo civilizatorio que recuerda a los mortales su distancia de los Inmortales. Desde otro horizonte, Delos y Delfos, las bien fundadas, las que han recibido la acción del Apolo fundador, son el paradigma de acción cultural por excelencia: el espacio salvaje convertido en tópos habitable, por medio del trabajo como impronta humana.

Apolo enseña a los hombres el arte de transformar lo salvaje en civilizado, de convertir el espacio inculto en el tópos culto de la ciudad.

Nuestro propósito consistió en abordar la figura de Apolo desde la complejidad que manifiesta la lógica que lo atraviesa. A la familiar consideración apolínea como el dios de la luminosidad oracular, entre otras marcas tendientes a presentarlo como una figura rectora de la genealogía olímpica, quisimos oponer una lectura tendiente a complejizar su figura, tensionando sus habituales rasgos identitarios.

Apolo está transido por un matiz de crueldad que tensiona otras marcas de identidad. Para ello recuperamos la interpretación de Giorgio Colli en El nacimiento de la Filosofía (1987) sobre la perversidad de Apolo y transitamos las huellas del reciente trabajo de Marcel Detienne, Apolo con el cuchillo en la mano. Una aproximación experimental al politeísmo griego (2001), rozando tangencialmente la lectura del libro I de la Ilíada para detectar dicha matriz.

El texto de Detienne resulta un hallazgo interensante a la luz de posiciones más tradicionales del helenista francés, históricamente ceñidas al modelo de interpretación estructuralista, que marcara fuertemente a los pensadores de la Ècole de Paris. Apolo parece mostrarle a Detienne la necesidad de abrir el análisis, de complejizarlo, de oxigenarlo de la clasificación binarizante que la lógica de la ambigüedad implica. En los

${ }^{27}$ Cf. Detienne, op. cit., 2001, p. 29. 
Maestros de verdad en la Grecia Arcaica $(1986)^{28}$ Detienne despliega el cuadro interpretativo que esa lógica exhibe para oponerla a la lógica de la no contradicción, propia del ulterior pensamiento filosófico.

Colli también se para frente a Apolo y advierte esa necesidad. Es a propósito de Apolo que surge en ambos la exigencia de una lectura más compleja, intersticial del fenómeno apolíneo. De hecho, cuando se instala frente a la lectura de Nietzsche en el Origen de la tragedia, Colli refuta la interpretación nietzscheana a partir de su unilateralidad.

Una tarea similar emprendimos con Dioniso, también para despejar la unilateralidad de una lectura que lo territorializa exclusivamente al tópos de la manía y de su consecuente resonancia con la hýbris. Los aportes del mismo Detienne avanzan en ese otro Dioniso capaz de fundar marcas civilizatorias.

Ambos dioses aparecen como figuras duales, ambiguas, complejas. Magma paradojal que parece ser una constante en el marco de la divinidad. Lo que en un pliegue resulta antitético, en otro instante se aproxima, evidenciando la riqueza semántica del universo divino. Dioniso y Apolo son sólo una muestra de la complejidad de la mitología griega que excede y transgrede cualquier tipo de clasificación binaria y reduccionista.

El atajo parece ser pensar en una "lógica de la complejidad", en donde cada dios no sólo se presenta junto a su opuesto, sino que también puede presentarse él mismo con una multiplicidad de rostros opuestos, aparentemente irreconciliables pero recuperados luego en la polisemia identitaria de la divinidad. Se trata así de dar cuenta de la dimensión microfísica, en términos de Michel Foucault, o molecular-rizomática, ${ }^{29}$ en términos Gilles Deleuze, de la mitología griega, de pasar del lógos propio del estructuralismo, amante de las clasificaciones binarias, al lógos del posestructuralismo, capaz de instalarse en la complejidad rizomática de cada fenómeno.

Entender la lógica del mito es entender su complejo entramado, ya que expresa de muchas formas la complejidad social. El mito no se desentiende de lo social, sino que, íntimamente articulado, forma con lo social un maridaje. En esta línea debe entenderse el reproche de Clastres al estructuralismo, cuando lo acusaba de haber

\footnotetext{
${ }^{28}$ La totalidad del texto se juega en el horizonte de esa lógica como marco interpretativo; no obstante la presentación de la tensión entre ambas lógicas aparece en el capítulo I "Verdad y Sociedad".

${ }^{29}$ Cf. Deleuze, G.; Guattari, F. Mil mesetas. Valencia: Pre-Textos, 1997, p. 215.
} 
olvidado la dinámica de lo social en aras de la quietud de la estructura. ${ }^{30}$ En la misma línea, las observaciones de Vernant reafirman la complejidad del mito cuando advierte que el estudio estructural de la religión debe incorporar necesariamente el estudio ${ }^{31}$.

Es esta articulación entre mito y sociedad la que permite dotar al mito del dinamismo propio de los análisis históricos y no congelarlo en un horizonte donde el análisis estructural impide las movilidades propias de la complejidad que lo caracteriza.

\section{Referencias}

BELLELI, C.; GARRETA, M. La trama cultural. Textos de Antropología. Buenos Aires: Caligraf, 1999.

CLASTRES, P. Investigaciones en antropología política. Barcelona: Gedisa, 2001.

COLLI, G. El nacimiento de la filosofía, Barcelona: Tusquets, 1987.

DELEUZE, G.; GUATTARI, F. Mil mesetas. Valencia: Pre-Textos, 1997.

DETIENNE, M. Apolo con el cuchillo en la mano. Una aproximación experimental al politeísmo griego. Madrid: Akal, 2001.

. Dioniso a cielo abierto. Barcelona: Gedisa, 1986a.

. Maestros de verdad en la Grecia Arcaica. Madrid: Taurus, 1986b.

FOUCAULT, M. Microfísica del poder. Madrid: Ediciones La Piqueta, 1995.

GERNET, L. Antropología de la Grecia antigua. Madrid: Taurus, 1981.

Himnos Homéricos y la Batracomaquia. Traducción de Alberto Bernabé Pajares. Madrid: Biblioteca Básica Gredos, 2001.

\footnotetext{
${ }^{30}$ Cf. Clastres, P. Investigaciones en antropología política. Barcelona: Gedisa, 2001, p. 170.

${ }^{31}$ Cf. Vernant, J.-P. Entre bestias y dioses. In: . Mito y pensamiento en la Grecia antigua. Barcelona: Ariel, 2001, p. 153.
} 


\section{nuntius antiquus}

HOMERO. Ilíada. Traducción de Emilio Crespo Güemes. Madrid: Gredos, 2000.

OTTO, W. Dioniso. Mito y Culto, Madrid: Siruela, 1997.

VERNANT, J.-P. La muerte en los ojos. Buenos Aires: F.C.E., 2000.

_. Mito y pensamiento en la Grecia antigua. Barcelona: Ariel, 2001. 